\title{
Company performance improvement by quality based intelligent-ERP
}

\author{
Kouroush Jenab $^{a^{*}}$, Selva Staub ${ }^{b}$, Saeid Moslehpour ${ }^{c}$ and Cuibing $W_{u^{a}}$
}

${ }^{a}$ Department of Engineering and Technology Management, Morehead State University, KY, USA

${ }^{b}$ Department of International Trades and Logistics, Bandırma Onyedi Eylül Üniversity, Turkey

${ }^{c}$ Department of Electrical and Computer Engineering, Hartford University, CT, USA

\begin{tabular}{l}
\hline C H R O N I C L E \\
\hline Article history: \\
Received April 3, 2018 \\
Received in revised format: \\
July 10, 2018 \\
Accepted July 25, 2018 \\
Available online \\
July 25, 2018 \\
\hline Keywords: \\
Company operations \\
Quality \\
Intelligent based ERP \\
Decision tree \\
Machine learning
\end{tabular}

\begin{abstract}
A B S T R A C T
The purpose of this paper is to examine the extent to which the Intelligent Enterprise Resource Planning (I-ERP) System can be used in company operations. Machine learning is embedded in a decision tree algorithm to demonstrate the viability of intelligent technology in an ERP system and to enhance the quality of operations through an I-ERP system. The study consists of two steps. In the first step, the algorithm uses the decision tree algorithm to demonstrate the application of intelligent technology in an ERP system. In the second step, the proposed model analyzes four quality criteria related to company operations through I-ERP system in order to determine whether or not I-ERP has significant improvement on managers' decisions. As a result, the use of I-EPR may improve the quality of operations, agile respond to market demand, increase the efficiency and the competitiveness in organizations. An illustration example is provided to demonstrate the application of I-ERP.
\end{abstract}

C 2018 by the authors; licensee Growing Science, Canada.

\section{Introduction}

There are many kinds of systems used in company operations, such as office automation (OA), supplier relationship management (SRM), customer relationship management (CRM), manufacturing execution system (MES), and enterprise resource planning (ERP). They assist companies in establishing high performance operations. Today, we can use the intelligent technology in these systems to make a positive impact on our daily lives. Furthermore, these new systems are smart, allowing firms to record more useful information with autonomic and predictive intelligent assets. This enhanced ERP is called "intelligent ERP" or "I-ERP", which will help the company make better business decisions and generate innovation. I-ERP systems that apply machine learning are set to be the next generation of ERP. Such a system may support the digital transformation of companies with new technology in enterprise systems.

Since ERP is an information technology system that collects information from the entire enterprise, it would be an asset to managers to control their companies' operations via the monitoring of every function and process, such as orders, inventory management, materials, and financials (Mehrjerdi, 2010). The use of ERP has positively improved the adoption of e-business functions in supply chain

\footnotetext{
* Corresponding author. Tel: (606) 783-9339, Fax: (606) 783-5030

E-mail address: k.jenab@moreheadstate.edu (K. Jenab)

(C) 2019 by the authors; licensee Growing Science, Canada. doi: $10.5267 / \mathrm{j}$.dsl.2018.7.003
} 
integration in 4,570 European companies (Nurmilaakso, 2008). It brings new opportunities and knowledge for their users, which increases user learning ability (Bendoly et al., 2009).

ERP can support the automation of processes, handle data, and control company operations more easily (Chapman, 2009; Kim, 2009; Stratman, 2007). It helps the organization and users save time by aggregating massive data sets from the entire company, thereby increasing the ability of calculations that results in more informed decision-making. When ERP meets business intelligence, it would be used by managers to make strategic decisions (Chou \& Chang, 2008). In this respect, ERP is a platform that leads to cost savings, improved processes, and better information accumulation to enhance competitiveness (Seddon, 2005).

ERP is now a support actor in improving the quality of reporting, the collection, and analysis of corporate data. Simply put, it is an effective way to control company operations (Chapman \& Kihn, 2009). Furthermore, machine learning and predictive analytics can assist ERP in improving processes and predictions, enhancing planning for company operations via learning from experience, and adapting business rules (Rizza, 2016).

ERP systems help create management systems that optimize operation flows in short production periods, reduce costs, accelerate fund turnover, and increase production and service quality (Ma, 2009). The competitive position of an organization may be enhanced by implementing the ERP system, successfully, based on well-designed strategy and satisfaction of customer needs, which can assist company's in reducing costs and increasing income (Ahmad, 2013; Kaniadakis, 2012; Mengistie, 2012; Moln et al., 2013). Today, sociotechnical systems play a vital role in company operations, and when used in companies, they serve an interdisciplinary function. They can increase employee satisfaction and company performance, while providing the support requirements to ensure effective implementation of an ERP system (Ghosh \& Sahney, 2010). Management should understand the benefits and return rate of ERP implementation and the costs associated with ERP systems (Dey et al., 2010). Organizational leaders should calculate the payback period to measure the value of the IT investment (Drumea \& Baba, 2008). Since companies are increasingly using new technology in their operations, ERP would be the most important tool to connect with their suppliers, customers, and business transactions. By integrating intelligent technology into ERP, the newly developed I-ERP will be an effective management tool in the future (Horakova \& Skalska, 2013; Kahraman et al., 2011).

\section{Problem Description}

Companies diligently improve their operations in order to be competitive in the global market. They employed tools, techniques, training, and re-organization to achieve high quality operations. This study aims at analyzing the feasibility of I-ERP system application, and whether such a system can satisfy quality criteria of the company's operation. Therefore, the following aspects must be addressed:

- Feasibility of integrating the intelligent technology and machine learning in ERP system,

- Effectiveness of I-ERP system for quality improvement of the company's operation.

\section{Methodology}

A Decision Tree is employed to examine whether intelligent technology can be integrated with an ERP system, resulting in an I-ERP system. The Integrating Machine Learning (ML) into an I-ERP application can enhance efficiency in predicting, learning, processing, and utilizing company resources and business practices. I-ERP system helps users create an interface with in-memory computing technology, which can aid in key information gathering and business adjustment procedures. Also, the features help the company gain a more clear future with the intelligent ERP systems via the collection of important operational data. I-ERP system provides forecasting solutions and builds predictive problem-solving means to use information that supports company development. Furthermore, as I-ERP 
software studies the organization operations, it not only adapts user interfaces but also adjusts strategies to increase efficiency. A decision tree is a form of supervised algorithm and it is always used in category problems via machine learning technology. It utilizes different input and output variables that are classified and continuous. Samples are divided into several congeneric sets with this technique. Sample sets are found on the significant splitter in the input variables (Shaikh, 2017). A decision tree depicts outcomes of the series choices that permits an organization to make possible comparisons against other companies vis a vis profits and costs. This technique usually begins with a single node and then it branches into the following outcomes; every output leads to different nodes which branch into other conditions. The resulting image resembles a tree. Important nodes are used to make sure which ones are best to guide decision-making. Using an I-ERP system, the quality of company operations can be analyzed based on four quality operations criteria: Quality of production process, speed of operation, flexibility, and cost (Thomas et al., 1985).

\subsection{ERP systems and Business Intelligence (BI)}

The ERP system is a package of software products merged together to support business processes such as budgeting, order fulfillment, finance, human management, production, supply chain, logistics, sales, and customer service (Amalnick et al., 2011). There are different modules found in an ERP system that the company assesses its functions against each module. Each module is linked to others, as are the users from different departments to different functions in the company. They use the ERP system with the capability of viewing different areas of the company, with the most critical areas for monitoring being logistics and order fulfillment. The number of companies worldwide that have implemented ERP is reported to be more than 30,000. See the Fig. 1.

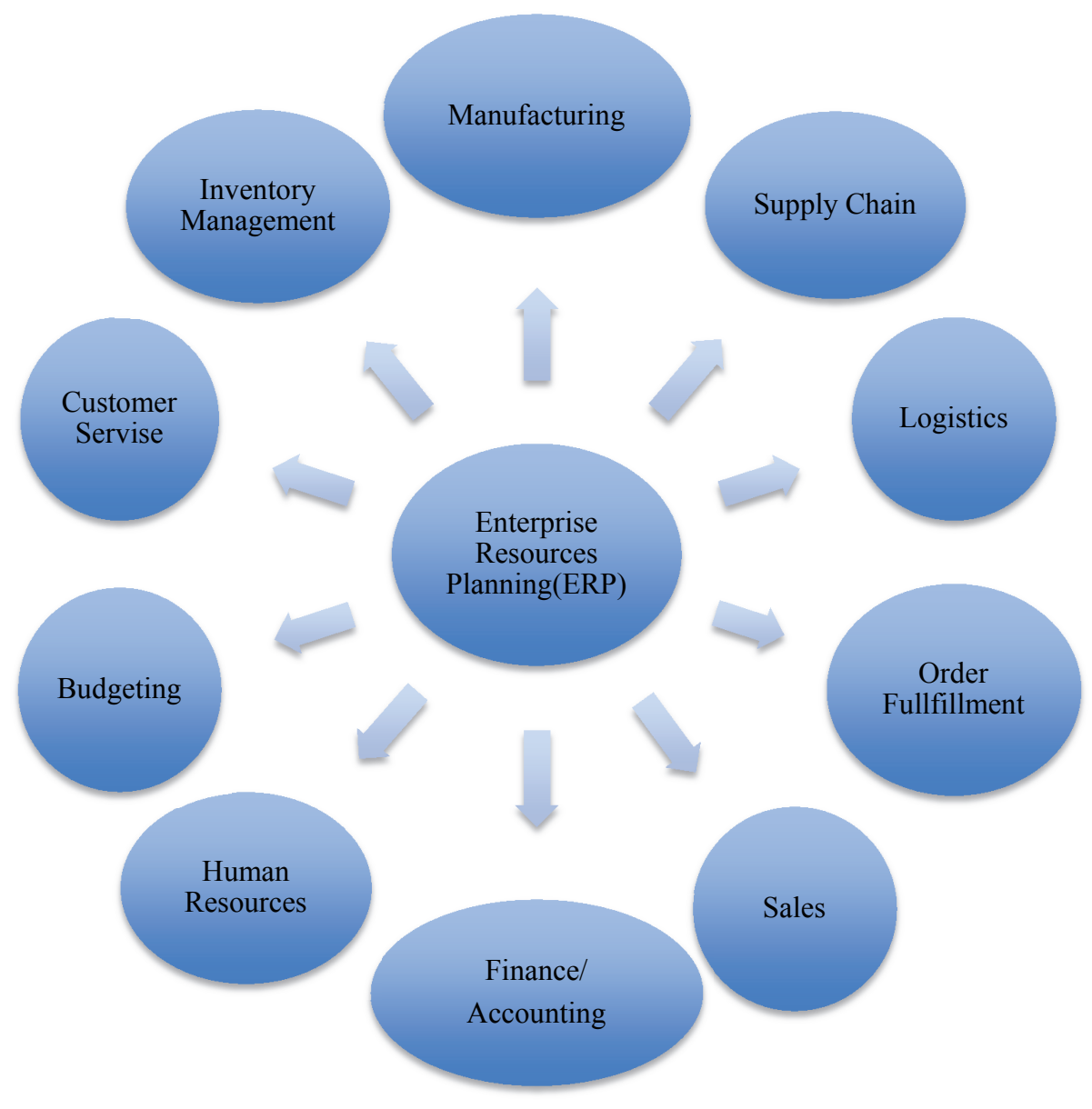

Fig. 1. Components of an ERP system 
To provide targeted decision-making, there is also new technology called Business Intelligence (BI) that combines data and analytical tools to utilize the methodologies and information given from data via the business knowledge (Horakova \& Skalska, 2013). The basic characteristics of BI make an umbrella term that covers data, analytical tools, and methodologies (Amalnick et al., 2011). BI, by tapping into multiple databases within a firm, offers management a more effective decision-making tool; data from the company operational databases that is fed into strategic decisions (Horakova \& Skalska, 2013). BI tools allow management better access to data, resulting in better decision making $(\mathrm{Wu}, 2010)$. One of the essential goals of any enterprise is effective decision-making. Accurate decisions depend on diverse data sources provided from information systems, such as Enterprise Resource Planning systems (Kahraman et al., 2011).

\subsection{Intelligent ERP (I-ERP) systems}

This study connects BI and ERP systems to assist enterprise managers in making effective decisions. I-ERP system creates results from the data collected and arranged through techniques such as machine learning and other advanced analytics. For instance, machine learning would help to identify unexpected customer behaviors. Effective analytics can help a company locate more useful information and progress further than ever before. I-ERP system will provide important information via the exceptions and business rules with the collected data (Ledford, 2017).

\subsection{Company operation}

Company operations keep the company running and generating revenue through its core processes. Operations are responsible for business functions and management of those operations focused on the creation of goods and services. Operations include managing equipment, capital, information, and all other resources that are needed in the processes related to the production of goods and services, as well as the management of people. Operations is therefore the most important function of every company as depicted in Fig. 2 (Sanders, 2014).
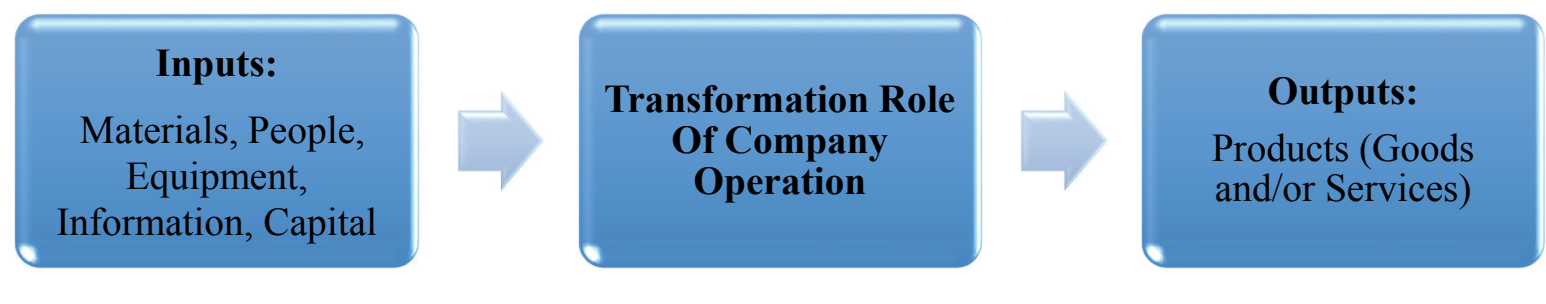

Fig. 2. The transformation role of company operation

\subsection{Quality}

For the purpose of this research, quality is defined in relationship to company operations. Thomas et al. (1985) proposed the criteria of quality in company operations, identifying four criteria: Quality of production process, speed of operation, flexibility, and cost. For all employees, they have an obligation to maintain quality in production. In another word, they have to keep quality in their mind in order to makeing sure that their works leads to high quality in all operations (Balle, 2015). 


\subsection{A Case study with the Machine Learning Method}

Machine learning is a kind of computer science to provide computer systems with an ability to "learn" with data, and no need to be programmed (Koza et al., 1996). With this form of data analytics, it is a method used to design complex models to make predicted decisions. Also, it can be used in the business field, known as the predictive analytics. Although machine learning generates effectiveness method, finding learning model is hard, and often training data is not sufficient (Simonite, 2017). Broadly, there are three types of machine learning algorithms as shown in Fig. 3 (Ray, 2017).

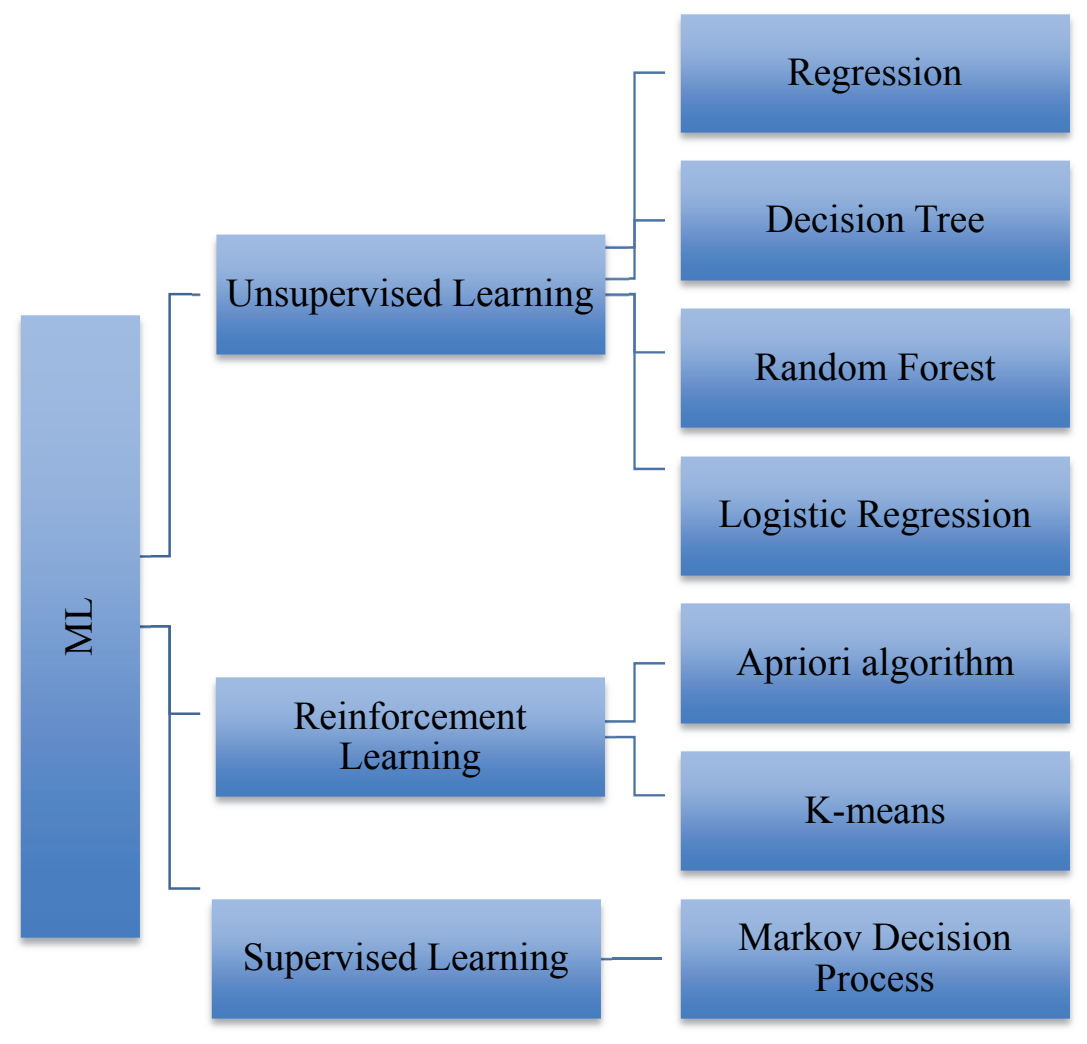

Fig. 3. Categories of Machine Learning

There are three kinds of nodes: chance, decision, and end. The chance nodes show the probabilities of certain results. The decision nodes show a decision to be made, and the end node shows the final outcome of a decision path. Decision Tree nodes are shown in Fig. 4 (Sathiyamoorthi \& Bhaskaran, 2009).

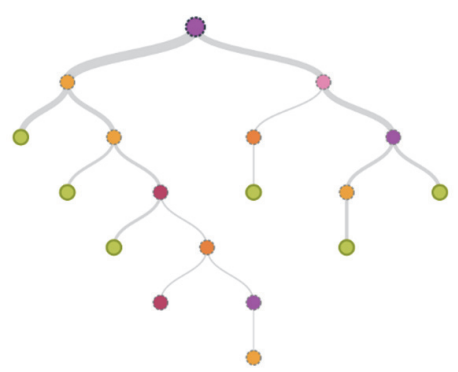

Fig. 4. Decision Tree

Here, this study used C4.5 method, which is one method of decision tree implementation. This method uses information gathered to measure different training sets and subset splits. Then let $p$ be the number of operating states and $n$ be the number of failed states included in the training set. Entropy E(p, n) of the set is defined as: 


$$
\mathrm{E}(\mathrm{P}, \mathrm{n})=-\frac{p}{p+\mathrm{n}} \log _{2} \frac{p}{p+\mathrm{n}}-\frac{n}{p+\mathrm{n}} \log _{2} \frac{n}{p+\mathrm{n}}
$$

\subsection{Using data to demonstrate an I-ERP system with a Decision Tree algorithm}

A step-by-step description of this algorithm is given below:

Step 1. Prepare previously arranged training data

A set of data selected from an ERP system database is used. For the data, the authors used EVA as the company performance index (also called decision attributes) and other indexes are the determinants (also called test attributes). The four indexes to identify the higher performance of the companies is used. The training data is shown in Table 1.

Table 1

Training Samples

\begin{tabular}{lccccc}
\hline Company & Income & Cost & Expense & Profit & EVA \\
\hline $\mathbf{A}$ & 24,400 & 15,400 & 850 & 6,800 & 7,000 \\
$\mathbf{B}$ & 15,500 & 11,400 & 150 & 3,500 & 6,800 \\
$\mathbf{C}$ & 15,900 & 14,100 & 120 & 1,600 & 880 \\
$\mathbf{D}$ & 13,200 & 11,200 & 10 & 1,300 & 11,100 \\
$\mathbf{E}$ & 20,800 & 15,100 & 1,280 & 2,900 & 10,800 \\
$\mathbf{F}$ & 11,000 & 8,000 & 880 & 2,120 & 1,470 \\
$\mathbf{G}$ & 23,100 & 312 & 5,100 & 10,010 \\
$\mathbf{H}$ & 28,800 & 7,900 & 660 & 2,800 & 6,700 \\
$\mathbf{I}$ & 12,200 & 2,120 & 560 & 360 & 780 \\
$\mathbf{J}$ & 3,200 & 4,800 & 170 & 1,000 & 900 \\
$\mathbf{K}$ & 6,300 & 7,300 & 760 & 3,180 & 7,510 \\
$\mathbf{M}$ & 11,700 & 17,800 & 760 & 4,170 & 3,500 \\
$\mathbf{N}$ & 25,400 & 4,300 & 450 & 1,000 & 890 \\
\hline
\end{tabular}

Unit: Thousand \$

For convenience, we classified these data via the conditions stated in Table 2. IF we satisfy the conditions shown in Table 2, we can change Table 1 to Table 3.

Table 2

Conditions of Table1

\begin{tabular}{l|l}
\hline Index & Conditions \\
\hline Income & If $<=10000$, Pass; If $>10000$ and $<20000$, Good; If $>=20000$, Great \\
\hline Cost & If $>=20000$, Pass; If $>10000$ and $<20000$, Good; If $<=10000$, Great \\
Expense & If $>=800$, Pass; If $>400$ and $<800$, Good; If $<=400$, Great \\
Profit & If $<=2000$, Pass; If $>2000$ and $<4000$, Good; If $>=4000$, Great \\
\hline EVA & If $<=5000$, Pass; If $>5000$ and $<10000$, Good; If $>=10000$, Great \\
\hline (Unit: Thousand \$)
\end{tabular}

\section{Table 3}

Training Samples

\begin{tabular}{|c|c|c|c|c|c|}
\hline Company & Income & Cost & Expense & Profit & EVA \\
\hline A & Great & Good & Pass & Great & Good \\
\hline B & Good & Good & Great & Good & Good \\
\hline $\mathbf{C}$ & Good & Good & Great & Pass & Pass \\
\hline D & Good & Good & Great & Pass & Great \\
\hline $\mathbf{E}$ & Great & Good & Pass & Good & Great \\
\hline F & Good & Great & Pass & Good & Pass \\
\hline $\mathbf{G}$ & Great & Pass & Great & Great & Great \\
\hline $\mathbf{H}$ & Good & Great & Good & Good & Good \\
\hline I & Pass & Great & Good & Pass & Pass \\
\hline $\mathbf{J}$ & Pass & Great & Great & Pass & Pass \\
\hline $\mathbf{K}$ & Good & Great & Good & Good & Good \\
\hline $\mathbf{L}$ & Great & Good & Good & Great & Pass \\
\hline M & Pass & Great & Good & Pass & Pass \\
\hline $\mathbf{N}$ & Great & Pass & Pass & Great & Great \\
\hline
\end{tabular}


Step 2. Building a decision tree node

We select the EVA as our decision attribute and the information of EVA is given as

$$
\mathrm{I}\left(\mathrm{s}_{1}, \mathrm{~s}_{2}, \mathrm{~s}_{3}, \ldots, \mathrm{s}_{\mathrm{m}}\right)=-\sum_{\mathrm{i}=1}^{\mathrm{n}} \mathrm{p}_{\mathrm{i}} \log _{2} \mathrm{p}_{\mathrm{i}}
$$

In Table 3, we can find that the companies of EVA have 4 Great, 4 Good, and 6 Pass. Then we can calculate the information of EVA with Eq.2:

$\mathrm{I}(4,4,6)=1.557$

Step 3. Calculate the expected information of the classified data samples selected.

The expected information needed to classify a given sample is given in Eq. (2).

For example: Income, we can gain the information of the Greats:

$\mathrm{I}(3,1,1)=1.37$

the information of Goods:

$\mathrm{I}(1,3,2)=1.46$

The information of Passes:

$\mathrm{I}(0,0,3)=0$

Step 4. Calculate the expected information of the test attribute selected

The entropy, or expected information based on the partitioning into subsets by attribute A, is given by

$$
E(A)=\sum_{j=1}^{w} \frac{s_{1 j}+s_{2 j}+\ldots+s_{n j}}{s} I\left(s_{1 j}, s_{2 j}, \ldots, s_{n j}\right)
$$

We can learn the Entropy of Income with the Eq. (3):

$\mathrm{E}($ Income $)=\frac{5}{14} \mathrm{I}(3,1,1)+\frac{6}{14} \mathrm{I}(1,3,2)+\frac{3}{14} \mathrm{I}(0,0,3)=1.12$

Step 5. Calculate the information gained of the test attribute selected

The encoding information that would be gained by branching on $\mathrm{A}$ is

$$
\operatorname{Gain}(A)=I\left(s_{1}, s_{2}, \ldots, s_{n}\right)-E(A)
$$

Gain $($ Income $)=1.557-1.12=0.437$

Then, we should calculate the Gain-Ratio with the formula below:

$$
\text { Gain-Ratio }(A)=\frac{\text { Gain }(A)}{\operatorname{Split~I(A)}}
$$

Split $\mathrm{I}($ Income $)=\mathrm{I}(5,6,3)=1.526$

Gain-Ratio (Income) $=0.437 / 1.526=0.286$

Step 6. Repeat steps 2-5 until the Gain-Ratio of the test attributes is completely calculated

Gain-Ratio $($ Cost $)=0.336$

Gain-Ratio(Expense $)=0.311$

Gain-Ratio(Profit) $=0.456$

Step 7. Select the highest Gain-Ratio of the test attribute to act as the node of partition for the decision tree 
In this case, the highest Gain-Ratio is Profit and we divide it into three sample sets as shown in Fig. 5 below:

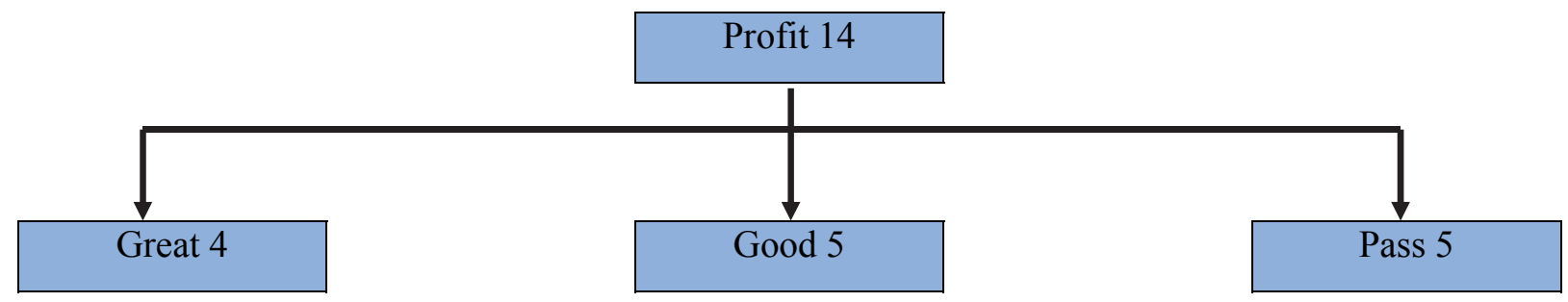

Fig. 5. Divide the sample into three sample sets with the Training Attribute Profit

Step 8. Complete these steps in order to establish the decision tree, follow this sequence of steps to find test attribute nodes at each level

In this step, we select the Profit. For the node, there are three groupings: 4 Great, 5 Good, and 5 Pass. When Profit is Pass, EVA has 4 Pass and 1 Great. So, we chose this node and there are 5 Pass via a majority voting method. And when the profit is Great, we arrive at the entropy of the last three conditions, which would be:

Gain-Ratio $($ Income $)=0$

Gain-Ratio $($ Cost $)=1$

Gain-Ratio (Expense) $=0.667$

Thus, we select Cost for the second node. Also for this node, there are two groupings: 2 Good and 2 Pass. In the same way, we select Income as the next node and when Profit is Good and Income is Great, EVA is Great. If Income is Good, we can see that EVA has 3 Good and 1 Pass. With the rule of majority voting method, we can receive the result that when Income is Good, EVA is 4 Good, as shown in Fig. 6. Then Expense can be selected for the next node of the decision tree. The result is depicted in Fig. 7.

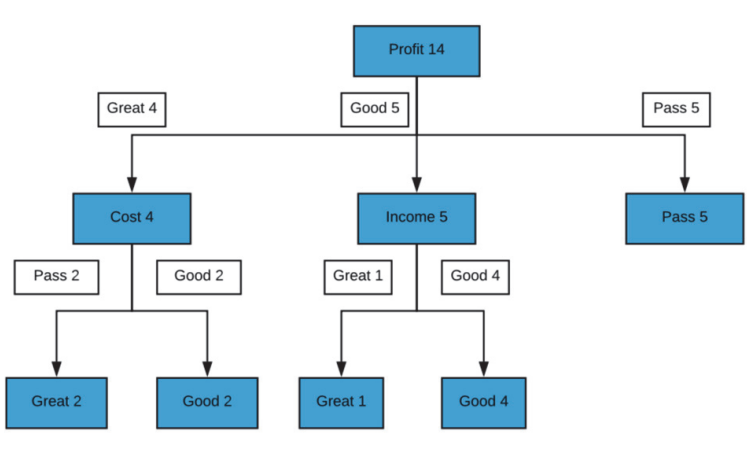

Fig. 6. Decision Tree

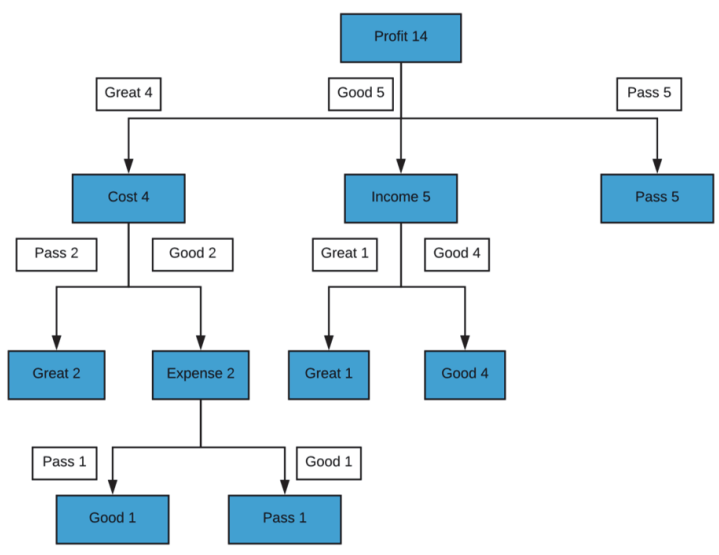

Fig. 7. Decision Tree

The knowledge rules possessed by the decision tree described above allow for the convenient gathering of information, by tracing this information along the path from root nodes to leaf nodes. These rules are described below:

$$
\begin{aligned}
& \text { IF Profit }=\text { "Pass" THEN EVA = "Pass" } \\
& \text { IF Profit }=\text { "Good" AND Income= "Great" THEN EVA = "Great" } \\
& \text { IF Profit }=\text { "Good" AND Income= "Good" THEN EVA = "Good" } \\
& \text { IF Profit }=\text { "Great" AND Cost }=\text { "Pass" THEN EVA = "Great" }
\end{aligned}
$$


IF Profit = "Great" AND Cost= "Good" AND Expense = "Pass" THEN EVA = "Good"

IF Profit = "Great" AND Cost= "Good" AND Expense = "Good" THEN EVA = "Pass"

Through the actual establishment of a decision tree with the data selected from the ERP system, the use of intelligent technology can be integrated into the ERP system. The use of the intelligent system in the company operations can enhance the efficiency of the company's decision making and quality improvement, and the experience has verified that I-ERP system permits effective integration of the vast number of transactions from the company's day-to-day business operations into the data warehouse system, which will become an important source of information to help decision-making. In sum, the company uses the I-ERP system to improve product quality, lower costs, and raise overall operational performance.

\section{The criteria of quality in company operation}

\subsection{Quality of the production process}

Quality is the most important outcome for a company. There are quality control (QC) and quality assurance (QA) systems to improve the production process, to decrease waste, to maintain equipment, and to meet customer satisfaction. In daily production, every aspect of the process is handled with ERP software; from acquiring and handling raw materials to the final product, to warehousing, and to distribution. Quality control has a close relationship with ERP, through specification of the control points and the limits to adhere to the system directly. The data can be entered and stored in the system, which can provide statistical process controls while also monitoring results and notifying users automatically. Also, these functions can be integrated into the intelligent ERP system to help workers understand where issues occur and how to address them. Such systems are fully integrated with purchase receipt functions, monitoring inventory, as well as work order processing in manufacturing. Quality assurance allows us to directly control factors linked with the production process, which can be controlled by the ERP system as it provides quality standards, compliance planning, fully integrated audit management, and integrated nonconformance reporting. When an I-ERP system is used, it can help users receive early alerts and offer solutions. ERP is an important tool for controlling quality of production processes. If we connect the intelligent technology with ERP, the new system will help managers make more sound decisions. An I-ERP system can learn by itself through daily experience and the formulated requirements. Also, different schemes are available for managers to select. In this way, I-ERP is able to decrease the cost of production quality, improve the quality of production process, as well as provide real-time and predictive process quality information in order to lessen the risk of recalls.

\subsection{Speed of operation}

Modern companies greatly depend on modern technology to manage everyday operations. The ERP system, through a variety of functions is able to improve company operations and production. It is therefore understandable why so many companies have used the ERP system since 1990s. Different industries, however, require different functions, and an effective ERP system can help them meet their various needs. In communications, an I-ERP system can organize information processes because all of the data is in one system. The manager can utilize I-ERP to make competitive business decisions. Communications between different departments in the company are improved because different teams are no longer working on disconnected systems. In this way, employees can save time and boost the speed of operations. Inventory turnover is an indicator of speed of operations. Short production life cycles accelerate inventory turnover, thus reducing costs and improving the capital utilization ratio. Inventory turnover is an important metric in determining the time span of replaced or sold inventory over a specific period of time. Inventory turnover measures how fast a company is selling inventory that is calculated as the average inventory over sales or cost of goods sold. 
We can see from Eq. (6) that if the sale or cost of goods sold is greater, or the average inventory is smaller, the inventory turnover ratio will be higher, and a higher inventory turnover ratio is sign of efficient operations. Thus, the I-ERP system becomes an attractive planning tool for managers.

An I-ERP system will monitor the various operations of the supply chain and solve the inventory issues in time. In turn, helping the company meet customer needs while also projecting the future and providing indicators for company development. Effective management of the supply chain improves inventory processes. These functions can help a company improve the speed and quality of operations.

\subsection{Flexibility}

The ERP system provides numerous benefits including improved resource utility, reduced quality costs, improved vendor performance and decision-making capability, better customer satisfaction, and improved information accuracy (Shang \& Seddon, 2000). An I-ERP system is also of benefit to numerous industries because of its flexibility; the functions can adapt to the multiple needs of different companies. At present, with the evolution of the technology, intelligent ERP systems can be seamlessly adapted into companies. Flexibility is a key requirement in that discrete components of modular enterprise software are designed to work together. Many vendors wish to sell and install as much software functionality up front as possible. It is far less disruptive to purchase and implement more functionality as needed, realizing a smaller number of go-lives with an associated return on investment.The interfaces need to be consistent, user-friendly, and easy to customize so that the daily working environment fits employee needs. To maximize end-user productivity, that flexibility needs to be available for mobile devices as well.

\subsection{Cost}

The ERP system helps decrease the cost of operations and management with the use of real-time data. Operations can be managed with ERP solutions with the result of reduced delays and defects. There are many important influences of ERP system on company performance, such as, improved speed of operations, decreased manual work and reduced labor costs and production times. The effectively implemented ERP system can save much money. A cost comparison of Pre-installation and Postinstallation ERP systems is conducted below (Table 4 and Fig. 8), using a data set from a sample firm.

\section{Table 4}

Cost comparison of Pre-installation and Post-installation ERP system

\begin{tabular}{lllll}
\hline NO. & Cost Items & Pre-installation Cost & Post-installation Cost & Annual Savings \\
\hline $\mathbf{1}$ & Computer maintenance & 94,000 & 38,000 & 56,000 \\
$\mathbf{2}$ & Computer Hardware & 62,000 & 7,000 & 55,000 \\
$\mathbf{3}$ & Computer Development & 74,000 & 30,000 & 44,000 \\
$\mathbf{4}$ & Logistics and Purchasing & 525,000 & 210,000 & 315,000 \\
$\mathbf{5}$ & Manufacturing Cost & 729,000 & 120,000 & 609,000 \\
$\mathbf{6}$ & Regional service Cost & $1,260,000$ & 840,000 & 420,000 \\
$\mathbf{7}$ & Inventory Cost & 299,000 & 117,000 & 182,000 \\
\hline & Total Annual Cost & $3,043,000$ & $1,362,000$ & $1,681,000$ \\
\hline
\end{tabular}

\section{Unit: \$}

For many companies, one of the main barriers to lowering expenses and improving efficiency is leftover and misused inventory. The role of ERP software is to identify the slow-moving inventory and then work to reduce its time sitting on the plant floor. ERP software should work to accelerate the time-tomarket of such inventory by finding new and quicker ways to deliver services and products. An I-ERP system aggregates financial data collection into one database that provides real-time data. An I-ERP system can help managers analyze data and offer insights and predictive decisions to increase the probability of sound decision making for the firm. Such capability enhances competitiveness while 
increasing efficiency. When intelligent technology is used in tandem with an ERP system, I-ERP will help managers to devise plans to ensure optimal inventory with maximum cost reductions.

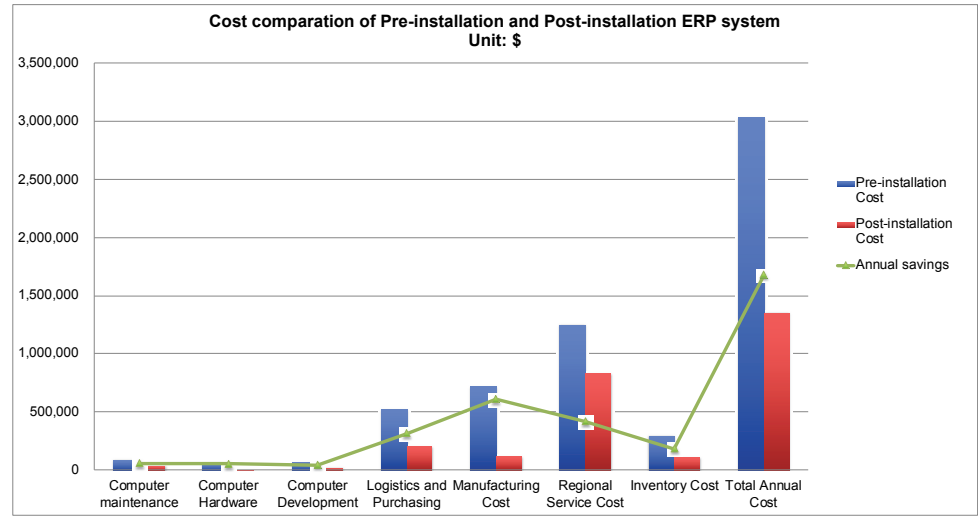

Fig. 8. Cost comparison of Pre-installation and Post-installation ERP system

\section{Results and Conclusion}

This study has examined one algorithm of Machine Learning, the Decision Tree, to demonstrate that intelligent technology can be combined with an ERP system. An I-ERP system can learn by itself and help managers make accurate decisions. When an I-ERP system is used in company operations, it can play a decisive role and support the firm's achievement of quality criteria. With the use of an I-ERP system, the quality of production processes are improved, the speed of operations is accelerated, flexibility is increased and costs decreased. An I-ERP system can help companies improve the quality of operations, meet market demands, increase efficiency, and improve product competitiveness. Although I-ERP system can enhance company operations, there are associated limitations to this study:

First, the research sample size is small. In this paper, only 14 training samples were used to establish a decision tree. However, the purpose of illustrating the use of a Decision Tree was not to be comprehensive, but rather to highlight its methodology in order to demonstrate that intelligent technology can be used with an ERP system. Second, the research lacks access to sufficient amounts of data to build a persuasive case. There are four criteria of quality in company operations. In analyzing these criteria, the researchers were unable to access sufficient amounts of data due to the small number of firms actually implementing I-ERP. In this paper, the researchers combined intelligent technology with ERP, and used the decision tree algorithm to analyze the possibility of carrying out such integration. In the future, by combining the information in this paper and the greater availability of data, the researchers hope to contribute to a growing body of knowledge that strengthens the case for integration of intelligent technology ERP. The results of this study lay the foundation for further exploration of the I-ERP system.

\section{References}

Ahmad, M. (2013). Critical success factors for ERP implementation in SMEs. Robotics and Computer-Integrated Manufacturing, 29(3), 104-111.

Amalnick, M. S., Ansarinejad, A., Nargesi, S. M., \& Taheri, S. (2011). New perspective to ERP critical success factors: Priorities and causal relations under fuzzy environment. The Journal of Mathematics and Computer Science, 2(1), 160-170.

Balle, L. (2015). What Is the Operations Segment of a Company? Retrieved from http://smallbusiness.chron.com/operations-segment-company-15269.html.

Bendoly, E., Rosenzweig, E. D., \& Stratman, J. K. (2009). The efficient use of enterprise information for strategic advantage: A data envelopment analysis. Journal of Operations Management, 27(4), 310-323.

Chapman, C. S., \& Kihn, L. A. (2009). Information system integration, enabling control and performance. Accounting, organizations and society, 34(2), 151-169. 
Chou, S. W., \& Chang, Y. C. (2008). The implementation factors that influence the ERP (enterprise resource planning) benefits. Decision support systems, 46(1), 149-157.

Dey, P. K., Clegg, B. T., \& Bennett, D. J. (2010). Managing enterprise resource planning projects. Business Process Management Journal, 16(2), 282-296.

Drumea, C., \& Baba, M. (2008). Deciding to implement an ERP solution based on performance indicators. Bulletin of the Transilvania University of Brasov. Economic Sciences. Series V, 1, 259.

Ghosh, K., \& Sahney, S. (2010). Organizational sociotechnical diagnosis of managerial retention in an IT organization: SAP-LAP framework. International Journal of Organizational Analysis, 18(1), 151-166.

Horakova, M., \& Skalska, H. (2013). Business intelligence and implementation in a small enterprise. Journal of systems integration, 4(2), 50-61.

Kahraman, C., Kaya, I., \& Çevikcan, E. (2011). Intelligence decision systems in enterprise information management. Journal of Enterprise Information Management, 24(4), 360-379.

Kaniadakis, A. (2012). ERP implementation as a broad socio-economic phenomenon: The agora of technoorganisational change. Information Technology \& People, 25(3), 259-280.

Kim, J. (2009). Activity-based framework for cost savings through the implementation of an ERP system. International Journal of Production Research, 47(7), 1913-1929.

Koza, J. R., Bennett, F. H., Andre, D., \& Keane, M. A. (1996). Automated design of both the topology and sizing of analog electrical circuits using genetic programming. In Artificial Intelligence in Design'96 (pp. 151-170). Springer, Dordrecht.

Ledford, J. (2017). How Intelligent Does Intelligent ERP Need to Be? Retrieved from https://it.toolbox.com/blogs/erpdesk/how-intelligent-does-intelligent-erp-need-to-be-052317.

Ma, Y. (2009). Research on the ERP/MES management system for dalian dituo zhonggong co.ltd (Order No. H282208) (1026764042). Retrieved from http://search.proquest.com/docview/1026764042? accountid=458.

Zare Mehrjerdi, Y. (2010). Enterprise resource planning: risk and benefit analysis. Business Strategy Series, 11(5), 308-324.

Mengistie, A. A. (2012). Analysis of the critical success factors for ERP systems implementation in U.S. federal offices (Order No. 3523280). Available from ProQuest Central; ProQuest Dissertations \& Theses Full Text. (1038140491). Retrieved from http://search.proquest.com/docview/1038140491?accountid=458.

Moln.r, B., Szab., Gy., \& Bencz.r, A. (2013). Selection process of ERP systems. Business Systems Research, 4(1). 36-48.

Nurmilaakso, J.M. (2008). Adoption of e-business functions and migration from EDI-based to XML-based e-business frameworks in supply chain integration. International Journal of Production Economics, 113(2), 721-733.

Ray, S. (2017). Essentials of Machine Learning Algorithms (with Python and R Codes). Retrieved from https://www.analyticsvidhya.com/blog/2017/09/common-machine-learning-algorithms/.

Rizza, M. N. (2016). The Rise of Intelligent ERP (i-ERP). Retrieved from https://idccommunity.com/groups/it_agenda/bigdataanalytics/the_rise_of_intelligent_erp_i_erp.

Sanders, N. (2014). Operations Management Defined. Retrieved from http://www.informit.com/articles/article.aspx?p=2167438.

Sathiyamoorthi, V., \& Bhaskaran, V. M. (2009). Data mining for intelligent enterprise resource planning system. International Journal of Recent Trends in Engineering, 2(3), 1.

Seddon, P. B. (2005). Are ERP systems a source of competitive advantage?. Strategic Change, 14(5), $283-293$.

Shaikh, F. (2017). A Complete Tutorial on Tree Based Modeling from Scratch (in R \& Python). Retrieved from https://www.analyticsvidhya.com/blog/2016/04/complete-tutorial-tree-based-modeling-scratch-in-python/.

Shang, S., \& Seddon, P. (2000). Comprehensive Framework for Classifying the Benefits of ERP Systems.Association for Information Systems Electronic Library (AISeL), Americas Conference on Information Systems (AMCIS).

Simonite, T. (2017). Microsoft says its racist chatbot illustrates how AI isnt adaptable enough to help most businesses. Retrieved from https:/www.technologyreview.com/s/603944/microsoft-ai-isnt-yet-adaptable-enough-to-helpbusinesses/.

Stratman, J. K. (2007). Realizing benefits from enterprise resource planning: does strategic focus matter?. Production and Operations Management, 16(2), 203-216.

Thomas, L. J., Hayes, R. H., \& Wheelwright, S. C. (1985). Restoring Our Competitive Edge: Competing through Manufacturing. Administrative Science Quarterly, 30(2), 305. doi:10.2307/2393118

$\mathrm{Wu}$, J.Y. (2010). Computational intelligence-based intelligent business intelligence system: concept and framework. 2nd International Conference on Computer and Network Technology, ICCNT 2010, pp. 334-338.

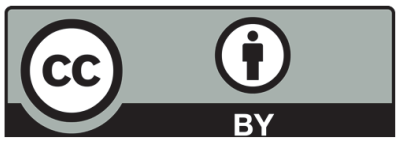

(C) 2019 by the authors; licensee Growing Science, Canada. This is an open access article distributed under the terms and conditions of the Creative Commons Attribution (CC-BY) license (http://creativecommons.org/licenses/by/4.0/). 